\title{
Left Ventricular Active Stiffness: Dependency on Time and Inotropic State
}

\author{
Piet Schiereck and Herman B. K. Boom* \\ Laboratory of Medical Physiology and Medical Physics, University of Utrecht, Vondellaan 24, Utrecht 2503, The Netherlands
}

\begin{abstract}
Left ventricular systolic stiffness was measured by rapidly changing ventricular volume (within $7 \mathrm{~ms}$ ) of isovolumically contracting isolated rabbit hearts. Instantaneous pressure-volume relations were found to be linear with slopes that depended upon the moment during contraction at which the volume change was induced. These slopes were proportional to the total pressure developed in the ventricle just prior to the volume change. The same was found when the time course of pressure was influenced by changing the $\mathrm{Ca}^{++}$content of the perfusate. An influence, however, also could be detected when end-diastolic volume was changed. At the same pre-release pressure a greater volume caused a decrease of active stiffness. The results indicate the possibility of an active component in ventricular systolic stiffness.
\end{abstract}

Key words: Quick volume release - Stiffness Pressure-volume relation - Left ventricle - Calcium.

\footnotetext{
*Present address: Twente Technical University, P.O. Box 217 , Enschede. The Netherlands.

Nr: $\quad$ number of experiment

H.W.: heart weight (g)

EDP: $\quad$ enddiastolic pressure $(\mathrm{mm} \mathrm{Hg})$

$\mathrm{Ca}^{++}: \quad \mathrm{Ca}^{++}$-content of the perfusate (mEq/l)

$\triangle \mathrm{P} / \Delta \mathrm{V}: \quad$ mean value of stiffness in systole in the part of pressure curve which was explored $(\mathrm{mm} \mathrm{Hg} / \mathrm{ml})$

$N$ : number of different times during systole at which QVR were applied

$P_{\max }$ : maximal pressure of the undisturbed pressure curve ( $\mathrm{mm} \mathrm{Hg}$ )

$\triangle \mathrm{V}_{0}: \quad$ inverted slope of the stiffness-pressure relations (ml)

SEM: $\quad$ standard error of the mean in $\Delta V_{0}$

$\frac{\Delta \mathrm{P}}{\Delta \mathrm{V}}\left(\mathrm{P}_{2}=0\right):$ intercept on $\Delta \mathrm{P} / \Delta \mathrm{V}$ axis of the stiffness pressure

SEE:

relation $(\mathrm{mm} \mathrm{Hg} / \mathrm{ml})$
standard error of the estimate in $\frac{\Delta \mathrm{P}}{\Delta \mathrm{V}}\left(\mathrm{P}_{2}=0\right)$
}

\section{Introduction}

Measurement of active stiffness of muscle is complicated by the fact that during contraction the mechanical state is changing rapidly. Assessment of elastic parameters therefore involves the determination of tension-elongation relations within a very short time. In dealing with heart muscle preparations such as papillary muscle, the quick-release technique has been widely used (Abbott and Mommaerts, 1959; Sonnenblick, 1964; Parmley and Sonnenblick, 1967; Pollack et al., 1972, 1976; Epstein et al., 1973; Grood et al., 1974; Meiss and Sonnenblick, 1974; McLaughlin and Sonnenblick, 1974; Krueger and Pollack, 1975; Glantz, 1975). The interpretation of results obtained with this method have been discussed until recently. This was due to the fact that the distribution over the length of the muscle of the induced length change was unknown. The damaged ends of the muscle were relatively extensible (Pollack and Krueger, 1976) and absorbed most of these length changes. Because of this there is no general agreement as to the time independency of myocardial series elasticity.

An alternative approach of this problem consists of measuring ventricular stiffness directly by applying rapid changes of ventricular volume. Only a few studies following this approach have been published until recently (Boom, 1971; Templeton et al., 1972; Covell et al., 1975). It has been claimed that ventricular series elasticity is time independent (Covell et al., 1975). This would support the view that this elastic element may be considered as a functionally separate, passive, component of heart muscle. These studies, however, had a restricted accuracy because of measuring errors and the slowness of the induced volume changes. In the present study a method is described which allows a more accurate determination of ventricular stiffness by rapidly pumping out small quantities of fluid from 
isolated rabbit hearts. This technqiue enables the determination of instantaneous pressure-volume relations that proved to be time dependent. A prelimenary report of this work has been published elsewhere (Schiereck and Boom, 1976).

\section{Methods}

Rabbits with a weight of $2,0-2.5 \mathrm{~kg}$ were anaesthetised with sodium pentobarbital; $30 \mathrm{mg}$ per $\mathrm{kg}$ body weight. Ventilation was maintained through a cannula tied into the trachea and connected to a breathing pump. Thoracotomy was performed and the portal vein was cut. A cannula was inserted after making a small slit in the ascending aorta just before the bifurcation. Care was taken that no air bubbles could penetrate the opened aorta. After complete removal of the heart the aortic cannula was connected to a perfusion system. The atria were removed and atrio-ventricular valves were cut. A small-fitting cannula was tied in the mitral orifice. Heart weight was between 5 and 10 grams. The hearts were perfused with a solution with the following composition in mEq/l $; \mathrm{Na}^{+}: 156.2 ; \mathrm{Ca}^{++}: 4.3 ; \mathrm{K}^{+}: 5.6 ; \mathrm{Cl}^{-}: 139.9$; $\mathrm{HCO}_{3}^{-}: 25.0 ; \mathrm{H}_{2} \mathrm{PO}_{4}^{-}: 1.2$; glucose: 11.7 ; saccharose: 13.1 .

Oxygenation of the perfusion fluid was affected by gassing with a mixture of $95 \% \mathrm{O}_{2}$ and $5 \% \mathrm{CO}_{2}$. The $\mathrm{pH}$ of the fluid was 7.36 at 32 degrees centigrade. Perfusion pressure was maintained at 6.67 $\mathrm{kPa}(50 \mathrm{~mm} \mathrm{Hg})$.

To obtain complete isovolumic contraction with a peak pressure exceeding that of the perfusion system, a counter valve was mounted into the perfusion cannula, just behind the aortic valves.

Diastolic pressure had to be kept at a fixed value. Therefore, during each diastole a special valve was opened which connected the left ventricle to a tube in which the height of the fluid column equal to the diastolic pressure desired could be controlled. The valve was opened for $100 \mathrm{~ms}$ before the next systole.

The Hiss bundle was destroyed by cauterizing, which reduced the intrinsic heart frequency to about $0.5 \mathrm{~Hz}$. Artificial stimulation enabled the synchronisation of experimental events relative to the cardiac cycle. Two silver plate electrodes each of $4 \mathrm{~cm}^{2}$ were used for stimulation of the heart. Stimulation current pulses were rectangular with a duration of $5 \mathrm{~ms}$ and a height of $10 \%$ above the threshold.

Through the mitral cannula the ventricle was connected to a small pump system with a stroke volume of $1.5 \mathrm{~cm}^{3}$. The diameter of the piston was $0.6 \mathrm{~cm}$. The position of the piston was controlled by an assembly consisting of a coil and a permanent magnet from a large loudspeaker and was measured by means of a position transducer (Hottinger Baldwin W 10, res. freq. $5 \mathrm{kHz}$ ). This signal was fed back into the driving amplifier, resulting in a servosystem for the movement of the piston (Figure 1). In this way left ventricular volume could rapidly be decreased at any moment in the cardiac cycle. This procedure will be called a quick volume release (QVR) experiment.

The pumpsystem was connected to a circuit by which the pumped volume could be increased each successive beat by $1 / 20$ of the maximal desired pump volume. The maximal volume decrease applied was $10-15 \%$ of enddiastolic volume (EDV). Systolic volume releases were followed by equal increases of volume during diastole. For measuring ventricular pressure the mitral cannula was connected to an electromanometer (Elema EMT34). Left ventricular pressure was also measured by making a $0.8 \mathrm{~mm}$ diameter hole in the apical wall and piercing a cathetertipmanometer (Millar PC $350 \mathrm{~A}$. res. freq. $15 \mathrm{kHz}$ ) into the ventricle. The signal of the Millar manometer was used further, the Elema manometer was only used for calibration of the cathetertipmanometer.

The experimental protocol was as follows:

First the electromanometer and the piston position transducer were calibrated. During this procedure the left ventricle contracted while the piston was not moved. After this a test series of 20

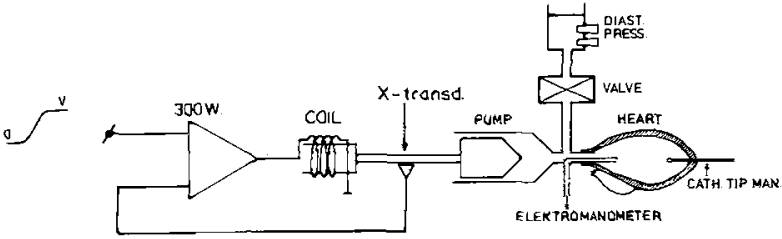

SET UP FOR INOUCING QUICK VOLUME STEPS.

Fig. 1. Schematic drawing of the quick volume release apparatus. Left ventricular pressure was measured by a cathetertip manometer (Milar PC 350A), which was calibrated by an electromanometer (Elema EMT84). Diastolic pressure was controlled during $100 \mathrm{~ms}$ prior to the next systole by opening a valve (VALVE) connected with a fluid column. A pumpsystem ( $P U M P$ ) was connected with the left ventricle through the mitral orifice. The position of the piston was measured by a transducer (X-transd) and fed back into a dryving amplifier (300W), which was connected with the coil of a loudspeaker, mounted on the bas of the piston. This displacement system enables piston movements according to time function with rise times greater than $5 \mathrm{~ms}$ at any time during systole or diastole
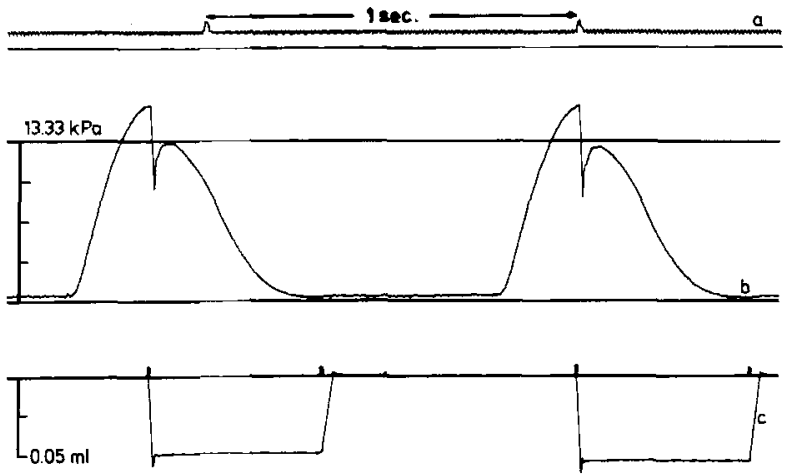

Fig. 2. Paper recording of two successive heartbeats with increasing quick volume releases at $P_{\max }$ followed by stretch in diastole. Note the different effects of the equal but opposite volume change in systole and diastole

successively increasing QVR's of the selected moment in systole was recorded. When it became regular, the next series was used for evaluation. Hereafter the time of occurance of QVR in the cardiac cycle was changed The first 20 beats were used again for checking purposes and the second 20 beats were used for evaluation. In this way a number of series of volume changes were recorded, each at another moment during the ascending limb of the pressure-time curve. The duration of such a protocol took less than $5 \mathrm{~min}$, including the calibration procedure. A new protocol was started after end diastolic pressure had been adjusted at another value and maximal pressure had become constant (in about $1 \mathrm{~min}$ ). After 3 protocols the first one was repeated. When the difference between the first and the last protocol exceeded $5 \%$ the protocols involved were disregarded.

The output of the pressure together with the displacement and timing signal were registered on an Elema multichannel recorder (EMT 81) (Fig. 2), sampled by a PDP8E computer and stored on digital tape. Generally a QVR was effected within $7 \mathrm{~ms}$. Pressure values directly following instaneous QVR could not be obtained by this method. An extrapolation procedure was used in order to estimate this value (Fig. 3). First the volume step magnitude $V_{1}-V_{2}$ and the time of completion of the volume change $\left(t v_{2}\right)$ are determined from the volume signal. $V_{2}$ is taken as the average of all saroples between $t v_{3}$ and $t v_{4}$. At $t v_{2}$ it is assumed that pressure has attained a 


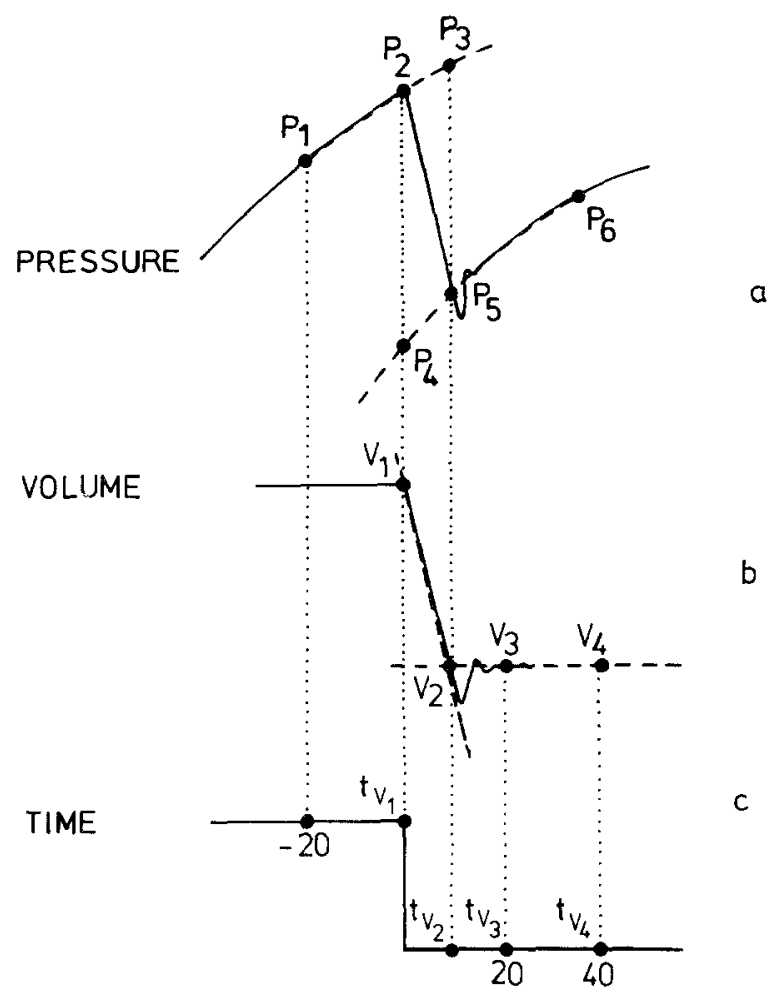

Fig. 3 a-c. The method of extrapolation used for assessment of QVR pressure differences in this study. (a) Pressure signal preceding, during and following QVR. Pressure difference as resulting from QVR can be identified was either $P_{2}-P_{4}$ or $P_{3}-P_{5}$. (b) Volume signal: $V_{1}$ : prerelease volume; $V_{3}-V_{4}$ : segment during which released volume is determined. (c) Timing signal: A step represents the voltage supplied to the piston drive system: $t_{1}:$ time of quick release; $t_{2}:$ moment at which quick release is completed; $t v_{3}-t v_{4}$ : period during which new QVR volume is assessed

value corresponding to the new volume. Using least square techniques a parabola was fitted to the released pressure signal from $P_{5}$ to $\mathrm{P}_{6}$ (chosen at $30 \mathrm{~ms}$ after $t \mathrm{~V}_{2}$ ). $\mathrm{P}_{4}$ is the extrapolated pressure at $t_{V_{1}}$ (time of quick release). Pre-release pressure $\left(\mathrm{P}_{2}\right)$ is assessed by likewise fitting of parabola from $P_{1}$ (taken $20 \mathrm{~ms}$ before $t_{1}$ ) to $\mathrm{P}_{2}$. $\mathrm{P}_{3}$ is the extrapolated pressure at $t \mathrm{~V}_{2}$. A quick release pressure step corrected for the time delay $t v_{1}-t v_{2}$ is identified with $\mathrm{P}_{2}-\mathrm{P}_{4}$. An alternative, but equally reasonable choice would be $\mathrm{P}_{3}-\mathrm{P}_{5}$. It appeared that resulting QVR pressure changes all differ by about $25 \%$ as did correspondingly, active stiffness. All other conclusions remained essentially unaltered. The material of this study is based on the choice of $\mathrm{P}_{2}-\mathrm{P}_{4}$. The procedure was accomplished automatically by the computer program which also evaluated the measurements.

Diastolic left ventricular pressure-volume relations were obtained by causing a complete block of the conduction system by means of the injection of saturated $\mathrm{KCl}$-solution in the ventricular septum. For measuring one pressure-volume data point, diastolic pressure was measured and volume was determined by establishing the amount of fluid that could be sucked from the ventricle by a syringe.

\section{Results}

Figure 2 shows two recorded beats during which fast volume changes were effected. The volume change occurred within $7 \mathrm{~ms}$. In this case volume change during contraction resulted in an almost instantaneous decrease of pressure to app. ${ }^{1 / 2}$ of its starting value. Note that a volume increase induced during the diastolic phase showed a neglegible effect on pressure. The last finding implies a very high compliance at that time as compared with systolic values. It was generally found that the diastolic/systolic compliance ratio which typically amounted to 50 or higher decreased during the experiment. Occasionaly preparations exhibited ratio's less than 25. Also, if an experiment was continued for several hours this ratio decreased gradually. Therefore this figure was felt to represent a measure of the quality of the preparation. Since also decreased diastolic compliance has been reported to indicate to be associated with hypoxy, all experiments that did not reach a preselected value (25) were discarded.

The way in which the pressure decrease depended on amount of volume release was investigated by increasing the volume change after each heart beat and plotting the resulting pressure $(\mathrm{P}-\Delta \mathrm{P})$ versus volume decrease $(\Delta V)$. This was repeated for different moments while diastolic pressure and the $\mathrm{Ca}^{++}$content of the perfusion fluid were kept constant. In this way a major part of the systolic curve was explored. The results for a particular experiment are shown in Figure 4a. In this experiment the maximal volume release was $0.1 \mathrm{ml}$. It appears from Figure $4 \mathrm{a}$ that the pressure-volume relationship thus found is linear to a very good approximation. It is also clear that at lower pre-release pressures (Fig. 3: $\mathrm{P}_{2}$ ) the effect of a given volume change is less than at higher pressure values. This indicates that ventricular volume stiffness increases at increasing pressure. This volume stiffness can be determined from the slope of the pressure-volume relations. Since it appears that these relations are linear, volume stiffness can be estimated by fitting the experimental points of Figure $4 \mathrm{a}$ with a family of straight lines (least squares approximation). Figure 4 a shows that these straight lines have a common intercept on the volume axis. This implies: 1 . That the quick volume change needed to produce zero pressure $\left(\Delta \mathrm{V}_{0}\right)$ is independent of the pressure existing before the change; 2 . That volume stiffness may be considered proportional to pre-release pressure. This last fact is in agreement with the finding that a QVR applied directly following stimulation, i.c. before pressure development, gives a negligible effect in the pressure recording, which was similar to the effect of the QVR during diastole. The above results are virtualy the same if the second extrapolation method is used (Fig. 4b). The only difference consists of a slight change of compliance. The constancy of $\Delta \mathrm{V}_{0}$ is illustrated more precisely by Figure $5 . \Delta \mathrm{V}_{0}$ was constant in the major part of the systole, except early $(<70 \mathrm{~ms})$ and later on in the relaxation. Figure 5 also shows the effects 

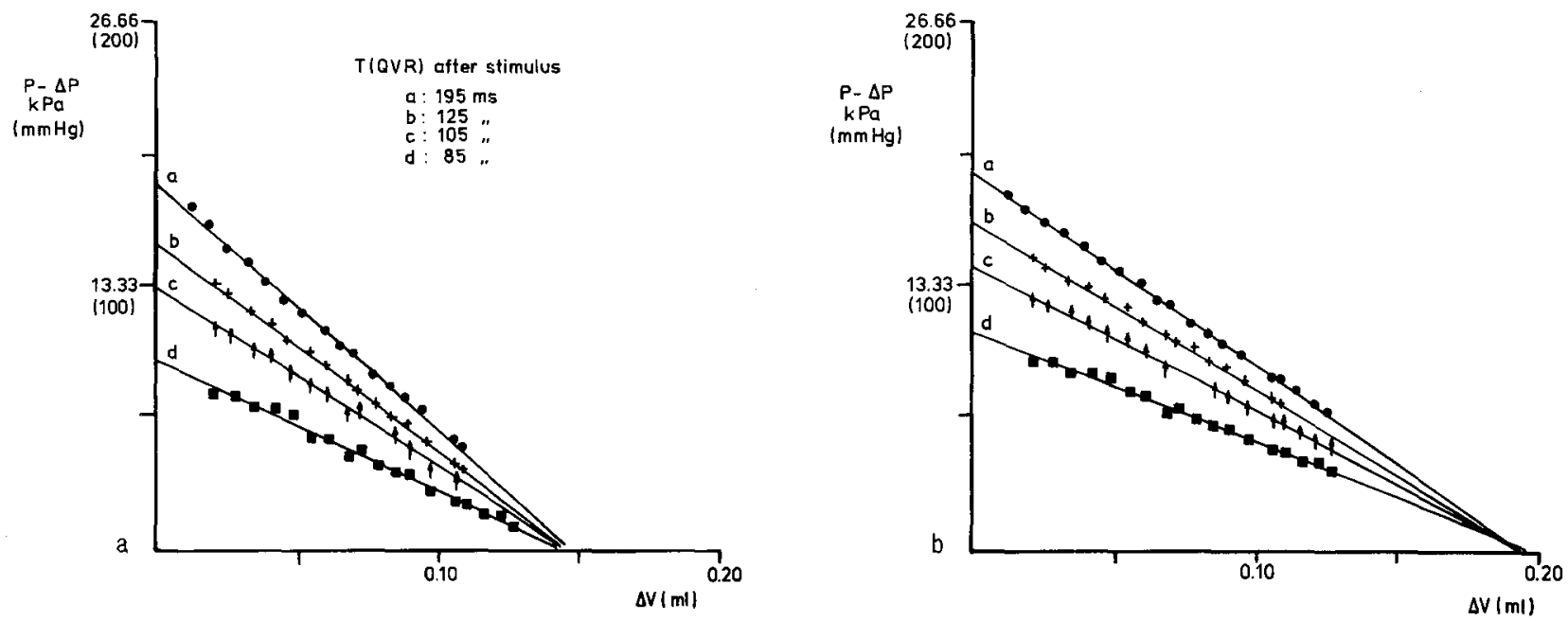

Fig. 4 a and b. Pressure-volume relationships obtained by quick volume releases at different times during systole. a calculated using $P_{2}-P_{4}$. b calculated using $\mathrm{P}_{3}-\mathrm{P}_{5}$ (see Fig. 3). Both methods show linear $\mathrm{P}-\mathrm{V}$ relation which extrapolated for $\mathrm{P}-\Delta \mathrm{P}=0$. corresponding to one value of $\Delta \mathrm{V}$

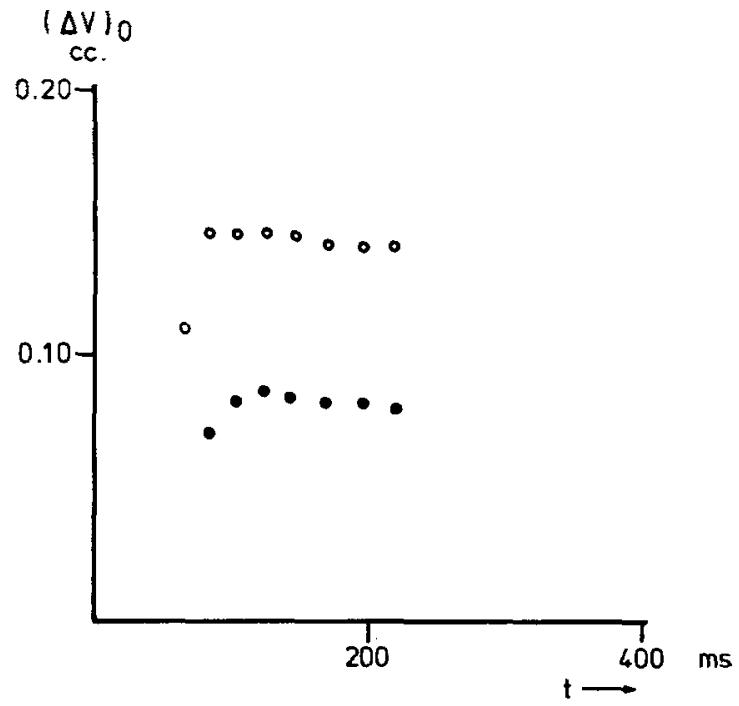

Fig. 5. Intercepts of the pressure-volume relations $\left(\Delta \mathrm{V}_{0}\right)$ for different moments in systole at different enddiastolic pressures, $\mathrm{O}: 4 \mathrm{~mm} \mathrm{Hg}$, -: $1 \mathrm{~mm} \mathrm{Hg}\left(P_{\max }\right.$ at $\left.t=200 \mathrm{~ms}\right)$. Intercept values were independent of time of release except for the earliest moments

of changing ventricular diastolic volume between two protocols (see Methods). At an increased diastolic volume $\Delta \mathrm{V}_{0}$ was appreciably greater but again, was independent of pre-release pressure $\left(\mathrm{P}_{2}\right)$.

This independence of $\Delta \mathrm{V}_{0}$ of pre-release pressure was not influenced by choosing different $\mathrm{Ca}^{++}$contents of the perfusion fluid. Figure 6 shows $\mathrm{P}-\Delta \mathrm{P} / \Delta \mathrm{V}$ releations measured at different $\mathrm{Ca}^{++}$concentrations but at the same time and enddiastolic pressures. Although a marked influence of $\mathrm{Ca}^{++}$on ventricular systolic compliance would be demonstrated, this influence implies a proportionality of slopes of the straight lines with $\mathrm{P}_{2}$.

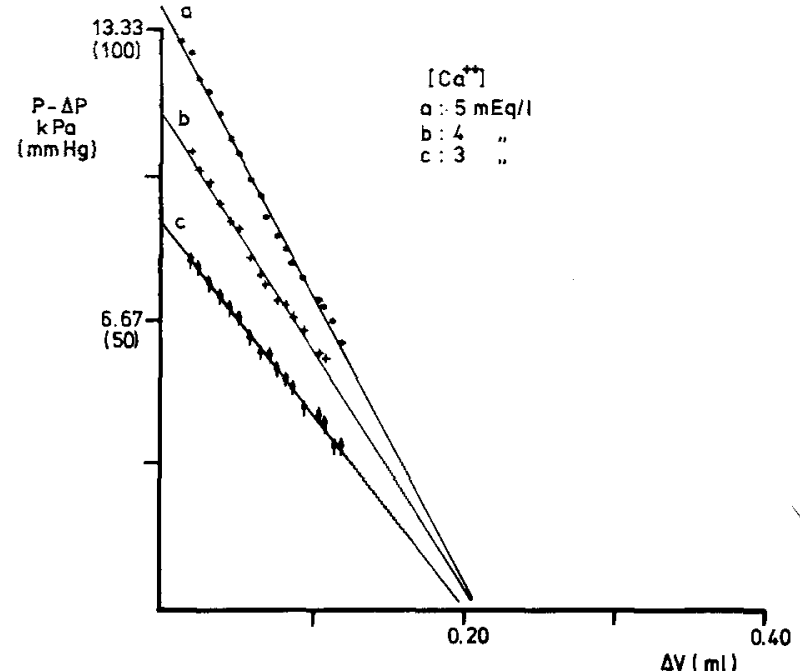

Fig. 6. Pressure-volume relations obtained at the same moment in systole, but different $\mathrm{Ca}^{++}$-contents of the perfusate

The influence of a change of $\mathrm{P}_{2}$ on $\Delta \mathrm{P} / \Delta \mathrm{V}$ as brought about by both changes in diastolic pressure and a changed $\mathrm{Ca}^{++}$content is shown in Figure 7. It is clear that although $\mathrm{Ca}^{++}$influences the mean position of the measured points as to their $\mathrm{P}_{2}$ coordinate, the net result is a shift along the linear $\Delta \mathrm{P} / \Delta \mathrm{V}-\mathrm{P}_{2}$ relationship. This is equivalent to an unchanged value of $\Delta \mathrm{V}_{0}$. This can be contrasted with the influence of diastolic pressure, an increase of which of 0 to $533.3 \mathrm{~Pa}$ $(4 \mathrm{~mm} \mathrm{Hg})$ caused increase of $\Delta \mathrm{V}_{0}=\mathrm{P}_{2} /(\Delta \mathrm{P} / \Delta \mathrm{V})$ from $0.11-0.24 \mathrm{~cm}^{3}$. The influence of $\mathrm{Ca}^{++}$content and diastolic pressure as found during this study are summarised in Table 1 and 2. Differences found for 

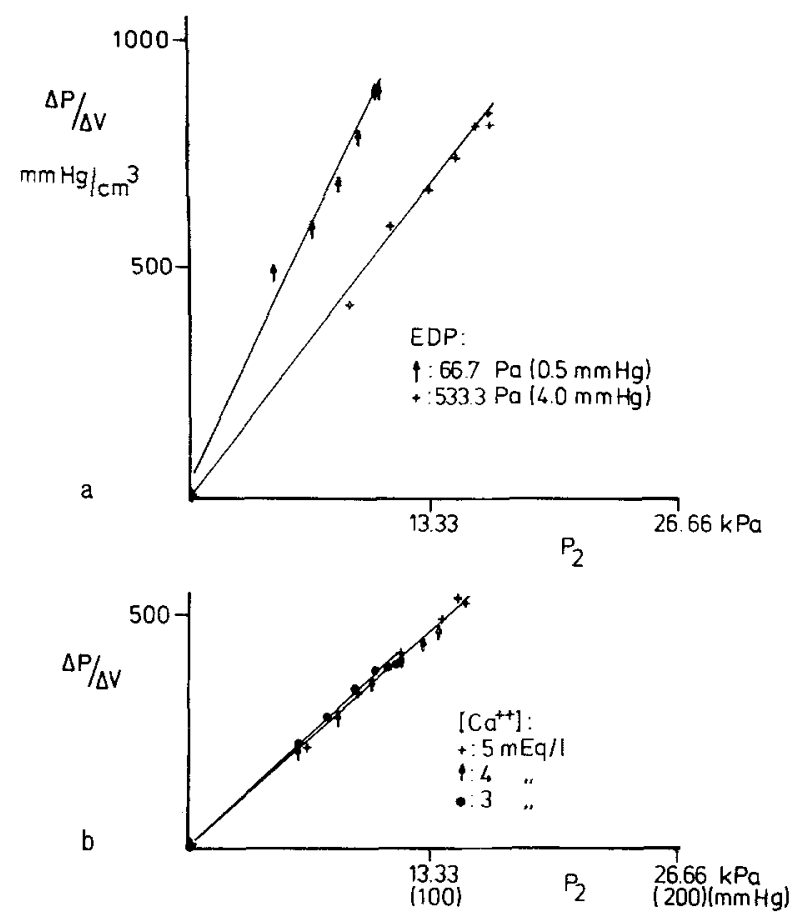

Fig. 7. a (top): Slopes of the pressure-volume relations as shown in Figure 4 a versus pre-release pressure $\left(\mathrm{P}_{2}\right)$ for 2 different enddiastolic pressures. b (bottom): The same as in Figure 7 a for 3 different $\mathrm{Ca}^{++}$. contents of the perfusate

values of $\Delta \mathrm{V}_{0}$ under identical conditions in different hearts can be, at least partly, attributed to variations of heart size. Friedmans test applied to samples of $\Delta \mathrm{V}_{0^{-}}$ values belonging to the same $\mathrm{Ca}^{++}$values could not demonstrate a significant influence of $\mathrm{Ca}^{++}$on $\Delta \mathrm{V}_{0}$.

The same procedure was carried out for $\Delta \mathrm{V}_{0}$-values in Table 2, taking samples of corresponding values of diastolic pressure. This influence was significant $(P$ $<0.001$ ). The dependence of $\Delta \mathrm{V}_{0}$ on diastolic pressure for different $\mathrm{Ca}^{++}$contents is summarised and visualised in Figure 8. All $\Delta \mathrm{V}_{0}$-values belonging to one value of diastolic pressure and one $\mathrm{Ca}^{++}$value were averaged and plotted together with their SEM. Note that no correction whatsoever for heart size was made. Except for end diastolic pressure $=0 \mathrm{Ca}^{++}$-content has no influence on the relationships of $\Delta \mathrm{V}_{0}$ and diastolic pressure.

\section{Discussion}

The assesment of ventricular compliance by way of fast volume changes is analogous to the quick release techniques known from skeletal and papillary muscle experiments. The method described in this study was already been used by Boom (1971) and is characterized by the application of long series increasing or decreasing volume steps during successive heart beats. In this

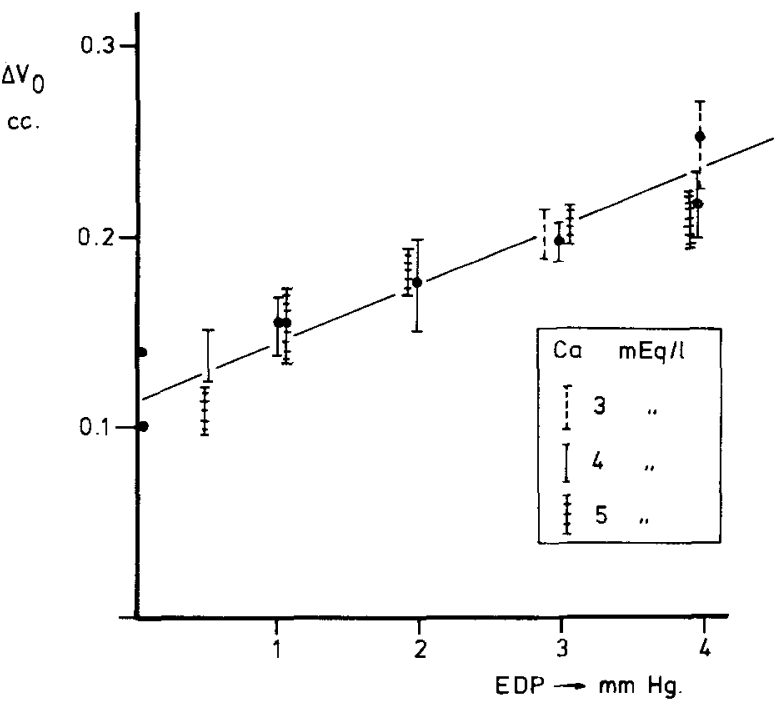

Fig. 8. $\Delta \mathrm{V}_{0}$ values of the linear stiffness-pressure relations for different $\mathrm{Ca}^{++}{ }_{-}$contents as a function of enddiastolic pressure. This plot was obtained by averaging $\Delta \mathrm{V}_{0}$ values from Table 1 and 2 corresponding with one EDP and one $\mathrm{Ca}^{++}$-content

way a large number of reliable measuring data can be obtained in a short time. Using this technique it was demonstrated that:

1. Systolic pressure-volume relations are almost linear (Fig. 4).

2. The quick volume release necessary for attaining zero pressure was independent of pre-release pressure (Fig. 5).

3. The relation between ventricular volume stiffness $(\Delta \mathrm{P} / \Delta \mathrm{V})$ and pre-release pressure which also was linear, was independent of the $\mathrm{Ca}^{++}$content of the perfusion fluid (Fig. 7).

4. Ventricular stiffness was markedly decreased if enddiastolic volume was increased (Fig. 7,8).

The present results were obtained from many series of successive disturbed beats in a relatively short time (15 s per protocol). Although the quick volume change was effected within $7 \mathrm{~ms}$ possible errors that could have been induced by this small delay were accounted for by the use of a sophisticated extrapolation technique. A check on the reliability of this extrapolation method was obtained by using an alternative method which gave equivalent results (Fig. $4 \mathrm{~b}$ ). It is therefore concluded that the results summarized above were not appreciably affected by the finiteness of the speed of the piston. The piston speed, however, could have been great, causing a non uniform distribution of the volume 
Table 1. Results from the QVR experiments for different $\mathrm{Ca}^{++}$-contents of the perfusate

\begin{tabular}{|c|c|c|c|c|c|c|c|c|c|c|}
\hline Nr. & H. W. & EDP & $\mathrm{Ca}^{++}$ & $\overline{\Delta \mathrm{P} / \Delta \mathrm{V}}$ & $N$ & $P_{\max }$ & $\Delta \mathrm{V}_{0}=\frac{\mathrm{P}_{2}}{\Delta \mathrm{P} / \Delta \mathrm{V}}$ & SEM & $\frac{\Delta \mathrm{P}}{\Delta \mathrm{V}}\left(\mathrm{P}_{2}=0\right)$ & SEE \\
\hline 1 & 7.8 & $\begin{array}{l}3.0 \\
3.0 \\
3.0\end{array}$ & $\begin{array}{l}5 \\
4 \\
3\end{array}$ & $\begin{array}{l}310 \\
299 \\
290\end{array}$ & $\begin{array}{l}8 \\
7 \\
7\end{array}$ & $\begin{array}{l}128 \\
126 \\
116\end{array}$ & $\begin{array}{l}0.288 \\
0.329 \\
0.299\end{array}$ & $\begin{array}{l}0.010 \\
0.029 \\
0.023\end{array}$ & $\begin{array}{r}-15.5 \\
28.6 \\
20.5\end{array}$ & $\begin{array}{l}15 \\
31 \\
28\end{array}$ \\
\hline 2 & 7.8 & $\begin{array}{l}4.0 \\
4.0 \\
4.0\end{array}$ & $\begin{array}{l}5 \\
4 \\
3\end{array}$ & $\begin{array}{l}362 \\
345 \\
313\end{array}$ & $\begin{array}{l}9 \\
9 \\
9\end{array}$ & $\begin{array}{l}141 \\
131 \\
122\end{array}$ & $\begin{array}{l}0.278 \\
0.284 \\
0.294\end{array}$ & $\begin{array}{l}0.007 \\
0.007 \\
0.010\end{array}$ & $\begin{array}{r}-15.0 \\
1.3 \\
17.3\end{array}$ & $\begin{array}{l}12 \\
11 \\
14\end{array}$ \\
\hline 3 & 5.8 & $\begin{array}{l}3.0 \\
3.0 \\
3.0\end{array}$ & $\begin{array}{l}5 \\
4 \\
3\end{array}$ & $\begin{array}{l}307 \\
333 \\
267\end{array}$ & $\begin{array}{l}7 \\
8 \\
7\end{array}$ & $\begin{array}{r}110 \\
111 \\
97\end{array}$ & $\begin{array}{l}0.257 \\
0.228 \\
0.234\end{array}$ & $\begin{array}{l}0.011 \\
0.006 \\
0.007\end{array}$ & $\begin{array}{r}11.3 \\
-\quad 2.7 \\
2.5\end{array}$ & $\begin{array}{l}17 \\
12 \\
12\end{array}$ \\
\hline 4 & 5.8 & $\begin{array}{l}4.0 \\
4.0 \\
4.0\end{array}$ & $\begin{array}{l}5 \\
4 \\
3\end{array}$ & $\begin{array}{l}371 \\
329 \\
266\end{array}$ & $\begin{array}{l}8 \\
8 \\
8\end{array}$ & $\begin{array}{r}117 \\
106 \\
88\end{array}$ & $\begin{array}{l}0.225 \\
0.228 \\
0.217\end{array}$ & $\begin{array}{l}0.008 \\
0.004 \\
0.006\end{array}$ & $\begin{array}{l}2.6 \\
8.3 \\
5.3\end{array}$ & $\begin{array}{r}16 \\
7 \\
11\end{array}$ \\
\hline 5 & 8.4 & $\begin{array}{l}3.0 \\
3.0 \\
3.0\end{array}$ & $\begin{array}{l}5 \\
4 \\
3\end{array}$ & $\begin{array}{l}419 \\
421 \\
349\end{array}$ & $\begin{array}{l}9 \\
9 \\
8\end{array}$ & $\begin{array}{l}128 \\
126 \\
108\end{array}$ & $\begin{array}{l}0.215 \\
0.207 \\
0.212\end{array}$ & $\begin{array}{l}0.006 \\
0.007 \\
0.011\end{array}$ & $\begin{array}{l}11.6 \\
15.8 \\
31.1\end{array}$ & $\begin{array}{l}19 \\
21 \\
27\end{array}$ \\
\hline 6 & 9.1 & $\begin{array}{l}3.0 \\
3.0 \\
3.0\end{array}$ & $\begin{array}{l}5 \\
4 \\
3\end{array}$ & $\begin{array}{l}433 \\
416 \\
362\end{array}$ & $\begin{array}{l}7 \\
7 \\
7\end{array}$ & $\begin{array}{l}128 \\
124 \\
109\end{array}$ & $\begin{array}{l}0.187 \\
0.193 \\
0.192\end{array}$ & $\begin{array}{l}0.007 \\
0.005 \\
0.007\end{array}$ & $\begin{array}{l}6.6 \\
6.9 \\
4.5\end{array}$ & $\begin{array}{l}22 \\
14 \\
18\end{array}$ \\
\hline 7 & 7.5 & $\begin{array}{l}3.0 \\
3.0 \\
3.0\end{array}$ & $\begin{array}{l}6 \\
4 \\
3\end{array}$ & $\begin{array}{l}311 \\
297 \\
164\end{array}$ & $\begin{array}{l}6 \\
6 \\
4\end{array}$ & $\begin{array}{r}111 \\
108 \\
51\end{array}$ & $\begin{array}{l}0.207 \\
0.207 \\
0.210\end{array}$ & $\begin{array}{l}0.018 \\
0.014^{-} \\
0.031\end{array}$ & $\begin{array}{r}-40.7 \\
-32.2 \\
10.3\end{array}$ & $\begin{array}{l}41 \\
31 \\
28\end{array}$ \\
\hline 8 & 6.2 & $\begin{array}{l}3.0 \\
3.0 \\
3.0\end{array}$ & $\begin{array}{l}6 \\
4 \\
3\end{array}$ & $\begin{array}{l}386 \\
302 \\
309\end{array}$ & $\begin{array}{l}6 \\
6 \\
6\end{array}$ & $\begin{array}{l}122 \\
111 \\
106\end{array}$ & $\begin{array}{l}0.211 \\
0.233 \\
0.221\end{array}$ & $\begin{array}{l}0.003 \\
0.012 \\
0.016\end{array}$ & $\begin{array}{r}-5.5 \\
19.3 \\
12.7\end{array}$ & $\begin{array}{r}7 \\
21 \\
31\end{array}$ \\
\hline 9 & 5.5 & $\begin{array}{l}1.0 \\
1.0\end{array}$ & $\begin{array}{l}6 \\
4\end{array}$ & $\begin{array}{l}550 \\
548\end{array}$ & $\begin{array}{l}14 \\
15\end{array}$ & $\begin{array}{l}111 \\
125\end{array}$ & $\begin{array}{l}0.149 \\
0.154\end{array}$ & $\begin{array}{l}0.006 \\
0.003\end{array}$ & $\begin{array}{l}-41.0 \\
-10.5\end{array}$ & $\begin{array}{l}31 \\
15\end{array}$ \\
\hline 10 & 8.8 & $\begin{array}{l}3.0 \\
3.0\end{array}$ & $\begin{array}{l}5 \\
4\end{array}$ & $\begin{array}{l}406 \\
371\end{array}$ & $\begin{array}{l}6 \\
8\end{array}$ & $\begin{array}{l}98 \\
85\end{array}$ & $\begin{array}{l}0.150 \\
0.160\end{array}$ & $\begin{array}{l}0.004 \\
0.004\end{array}$ & $\begin{array}{l}7.9 \\
9.1\end{array}$ & $\begin{array}{l}14 \\
11\end{array}$ \\
\hline
\end{tabular}

change within the ventricle. Such a non uniformity could lead to significant pressure deviations, if simultanous intracavital pressure is not uniform. A new pressure distribution could be the result of a non negligible transmission time of the pressure within the ventricle. This time can be estimated as follows: if the ventricle is roughly assumed to be cylindrical with the piston at one end, the transmission of a pressure pulse in such a cavity is approximately given by:

$$
v=\sqrt{\frac{V \cdot S}{\varrho}}
$$

in which $V$ is the summed ventricular and myocardial volume. $S$ is the mean volume stiffness during the period of pressure development as determined in this study and $\varrho$ is the density of the myocardium, which is assumed to be equal to the density of water. The above expression is easily derived from the well known equation of Korteweg (1878) as given by Jager (1965). Taking $V=8.0 \times 10^{-6} \mathrm{~m}^{3} . S=6.67 \times 10^{7} \mathrm{kPa} / \mathrm{m}^{3}$ and $=10^{3} \mathrm{~kg} / \mathrm{m}^{3}$ a value of $23 \mathrm{~m} / \mathrm{s}$ is found for $v$. During the
QVR of $6 \mathrm{~ms}$ then a pressure pulse wave travels over a distance of $13.8 \mathrm{~cm}$. This is many times the length of the ventricle. It can be concluded that intraventricular pressure may regarded as distributed homogeneously throughout the ventricle at the end of the release. Pressure-volume curves comparable with those from the present study have been measured by Covell et al. (1975), who transformed the data to midwall stresses and extension of a postulated series elastic element situated in the ventricular wall. These stress extension relations were claimed to be exponential. The present study yielded linear relations between pressure and quick volume changes. The question arises whether this finding is compatible with such an exponential relationship. This can be judged in Figure 9 where the pressure-volume relations of the present study are transformed to stresses and extensions. This introduces some curvature as it is theoretically expected to do. The effect, however, is negligible. It appears that the results of the present study do not agree with the conclusions of Covell et al. The exponential found by these authors 
Table 2. Results from QVR experiments for different enddiastolic pressures

\begin{tabular}{|c|c|c|c|c|c|c|c|c|c|c|}
\hline Nr. & H.W. & EDP & $\mathrm{Ca}^{++}$ & $\Delta \mathrm{P} / \Delta \mathrm{V}$ & $N$ & $P_{\max }$ & $\Delta \mathrm{V}_{0}=\frac{\mathrm{P}_{2}}{\Delta \mathrm{P} / \Delta \mathrm{V}}$ & SEM & $\frac{\Delta \mathrm{P}}{\Delta \mathrm{V}}\left(\mathrm{P}_{2}=0\right)$ & SEE \\
\hline 1 & 8.0 & $\begin{array}{l}4.0 \\
1.0 \\
0.5 \\
0.0\end{array}$ & $\begin{array}{l}4 \\
4 \\
4 \\
4\end{array}$ & $\begin{array}{l}473 \\
445 \\
487 \\
339\end{array}$ & $\begin{array}{l}3 \\
3 \\
3 \\
3\end{array}$ & $\begin{array}{r}128 \\
117 \\
97 \\
78\end{array}$ & $\begin{array}{l}0.164 \\
0.155 \\
0.115 \\
0.139\end{array}$ & $\begin{array}{l}0.010 \\
0.008 \\
0.003 \\
0.028\end{array}$ & $\begin{array}{r}5.7 \\
5.7 \\
-\quad 3.7 \\
19.8\end{array}$ & $\begin{array}{l}36 \\
30 \\
18 \\
85\end{array}$ \\
\hline 2 & 8.0 & $\begin{array}{l}4.0 \\
1.0 \\
0.5 \\
0.0\end{array}$ & $\begin{array}{l}5 \\
5 \\
5 \\
5\end{array}$ & $\begin{array}{l}501 \\
400 \\
384 \\
400\end{array}$ & $\begin{array}{l}3 \\
3 \\
3 \\
3\end{array}$ & $\begin{array}{r}129 \\
98 \\
77 \\
67\end{array}$ & $\begin{array}{l}0.153 \\
0.142 \\
0.117 \\
0.101\end{array}$ & $\begin{array}{l}0.004 \\
0.001 \\
0.007 \\
0.012\end{array}$ & $\begin{array}{r}3.0 \\
-0.5 \\
6.2 \\
11.8\end{array}$ & $\begin{array}{r}16 \\
2 \\
29 \\
59\end{array}$ \\
\hline 3 & 6.9 & $\begin{array}{l}3.0 \\
0.5\end{array}$ & $\begin{array}{l}5 \\
5\end{array}$ & $\begin{array}{l}770 \\
932\end{array}$ & $\begin{array}{l}8 \\
9\end{array}$ & $\begin{array}{l}139 \\
121\end{array}$ & $\begin{array}{l}0.126 \\
0.086\end{array}$ & $\begin{array}{l}0.005 \\
0.005\end{array}$ & $\begin{array}{r}-33.8 \\
24.4\end{array}$ & $\begin{array}{l}39 \\
87\end{array}$ \\
\hline 4 & 6.9 & $\begin{array}{l}3.0 \\
0.5\end{array}$ & $\begin{array}{l}3 \\
3\end{array}$ & $\begin{array}{l}615 \\
656\end{array}$ & $\begin{array}{l}8 \\
8\end{array}$ & $\begin{array}{r}125 \\
78\end{array}$ & $\begin{array}{l}0.148 \\
0.090\end{array}$ & $\begin{array}{l}0.004 \\
0.004\end{array}$ & $\begin{array}{r}-3.7 \\
29.5\end{array}$ & $\begin{array}{l}21 \\
35\end{array}$ \\
\hline 5 & 6.9 & $\begin{array}{l}3.0 \\
1.0\end{array}$ & $\begin{array}{l}5 \\
5\end{array}$ & $\begin{array}{l}713 \\
675\end{array}$ & $\begin{array}{l}8 \\
8\end{array}$ & $\begin{array}{l}146 \\
123\end{array}$ & $\begin{array}{l}0.151 \\
0.133\end{array}$ & $\begin{array}{l}0.006 \\
0.007\end{array}$ & $\begin{array}{r}7.9 \\
-17.4\end{array}$ & $\begin{array}{l}32 \\
42\end{array}$ \\
\hline 6 & 6.9 & $\begin{array}{l}3.0 \\
1.0\end{array}$ & $\begin{array}{l}4 \\
4\end{array}$ & $\begin{array}{l}617 \\
532\end{array}$ & $\begin{array}{l}8 \\
8\end{array}$ & $\begin{array}{r}120 \\
91\end{array}$ & $\begin{array}{l}0.137 \\
0.126\end{array}$ & $\begin{array}{l}0.003 \\
0.009\end{array}$ & $\begin{array}{l}13.5 \\
25.7\end{array}$ & $\begin{array}{l}19 \\
45\end{array}$ \\
\hline 7 & 8.5 & $\begin{array}{l}3.0 \\
2.0\end{array}$ & $\begin{array}{l}5 \\
5\end{array}$ & $\begin{array}{l}629 \\
628\end{array}$ & $\begin{array}{l}9 \\
9\end{array}$ & $\begin{array}{l}139 \\
141\end{array}$ & $\begin{array}{l}0.162 \\
0.159\end{array}$ & $\begin{array}{l}0.005 \\
0.006\end{array}$ & $\begin{array}{l}19.3 \\
16.5\end{array}$ & $\begin{array}{l}28 \\
36\end{array}$ \\
\hline 8 & 8.5 & $\begin{array}{l}3.0 \\
2.0\end{array}$ & $\begin{array}{l}4 \\
4\end{array}$ & $\begin{array}{l}627 \\
610\end{array}$ & $\begin{array}{l}9 \\
9\end{array}$ & $\begin{array}{l}141 \\
144\end{array}$ & $\begin{array}{l}0.151 \\
0.164\end{array}$ & $\begin{array}{l}0.007 \\
0.006\end{array}$ & $\begin{array}{r}-18.4 \\
24.1\end{array}$ & $\begin{array}{l}45 \\
32\end{array}$ \\
\hline 9 & 8.5 & $\begin{array}{l}3.0 \\
2.0\end{array}$ & $\begin{array}{l}3 \\
3\end{array}$ & $\begin{array}{l}583 \\
618\end{array}$ & $\begin{array}{l}9 \\
9\end{array}$ & $\begin{array}{l}137 \\
134\end{array}$ & $\begin{array}{l}0.179 \\
0.171\end{array}$ & $\begin{array}{l}0.011 \\
0.016\end{array}$ & $\begin{array}{l}48.2 \\
81.4\end{array}$ & $\begin{array}{l}46 \\
72\end{array}$ \\
\hline 10 & 7.5 & $\begin{array}{l}4.0 \\
2.0 \\
1.0\end{array}$ & $\begin{array}{l}4 \\
4 \\
4\end{array}$ & $\begin{array}{l}450 \\
415 \\
346\end{array}$ & $\begin{array}{l}8 \\
7 \\
7\end{array}$ & $\begin{array}{r}126 \\
103 \\
78\end{array}$ & $\begin{array}{l}0.193 \\
0.185 \\
0.170\end{array}$ & $\begin{array}{l}0.008 \\
0.013 \\
0.014\end{array}$ & $\begin{array}{l}21.3 \\
38.5 \\
34.0\end{array}$ & $\begin{array}{l}25 \\
36 \\
33\end{array}$ \\
\hline 11 & 9.1 & $\begin{array}{l}3.0 \\
1.0\end{array}$ & $\begin{array}{l}4 \\
4\end{array}$ & $\begin{array}{l}366 \\
353\end{array}$ & $\begin{array}{l}13 \\
12\end{array}$ & $\begin{array}{l}93 \\
83\end{array}$ & $\begin{array}{l}0.211 \\
0.203\end{array}$ & $\begin{array}{l}0.011 \\
0.014\end{array}$ & $\begin{array}{l}35.0 \\
49.3\end{array}$ & $\begin{array}{l}24 \\
29\end{array}$ \\
\hline 12 & 6.2 & $\begin{array}{l}3.0 \\
2.0\end{array}$ & $\begin{array}{l}6 \\
6\end{array}$ & $\begin{array}{l}371 \\
374\end{array}$ & $\begin{array}{l}11 \\
11\end{array}$ & $\begin{array}{l}110 \\
113\end{array}$ & $\begin{array}{l}0.204 \\
0.203\end{array}$ & $\begin{array}{l}0.005 \\
0.005\end{array}$ & $\begin{array}{l}-6.5 \\
-14.0\end{array}$ & $\begin{array}{l}12 \\
13\end{array}$ \\
\hline 13 & 9.4 & $\begin{array}{l}3.0 \\
2.0 \\
1.0 \\
0.5\end{array}$ & $\begin{array}{l}6 \\
6 \\
6 \\
6\end{array}$ & $\begin{array}{l}386 \\
361 \\
317 \\
317\end{array}$ & $\begin{array}{l}6 \\
6 \\
6 \\
5\end{array}$ & $\begin{array}{r}136 \\
123 \\
104 \\
74\end{array}$ & $\begin{array}{l}0.246 \\
0.236 \\
0.218 \\
0.144\end{array}$ & $\begin{array}{l}0.018 \\
0.018 \\
0.023 \\
0.017\end{array}$ & $\begin{array}{l}-19.9 \\
-20.2 \\
-25.7 \\
-21.3\end{array}$ & $\begin{array}{l}35 \\
35 \\
44 \\
48\end{array}$ \\
\hline 14 & 9.4 & $\begin{array}{l}3.0 \\
2.0 \\
1.0 \\
0.5\end{array}$ & $\begin{array}{l}4 \\
4 \\
4 \\
4\end{array}$ & $\begin{array}{l}358 \\
350 \\
284 \\
272\end{array}$ & $\begin{array}{l}5 \\
6 \\
6 \\
5\end{array}$ & $\begin{array}{r}137 \\
125 \\
98 \\
67\end{array}$ & $\begin{array}{l}0.231 \\
0.229 \\
0.213 \\
0.160\end{array}$ & $\begin{array}{l}0.018 \\
0.009 \\
0.012 \\
0.009\end{array}$ & $\begin{array}{r}-28.5 \\
-15.8 \\
-17.7 \\
12.0\end{array}$ & $\begin{array}{l}39 \\
18 \\
21 \\
18\end{array}$ \\
\hline 15 & 9.4 & $\begin{array}{l}3.0 \\
2.0\end{array}$ & $\begin{array}{l}3 \\
3\end{array}$ & $\begin{array}{l}229 \\
234\end{array}$ & $\begin{array}{l}6 \\
6\end{array}$ & $\begin{array}{l}69 \\
65\end{array}$ & $\begin{array}{l}0.205 \\
0.189\end{array}$ & $\begin{array}{l}0.021 \\
0.018\end{array}$ & $\begin{array}{l}13.7 \\
15.5\end{array}$ & $\begin{array}{l}28 \\
27\end{array}$ \\
\hline 16 & 5.6 & $\begin{array}{l}3.0 \\
2.0 \\
1.0\end{array}$ & $\begin{array}{l}4 \\
4 \\
4\end{array}$ & $\begin{array}{l}650 \\
588 \\
471\end{array}$ & $\begin{array}{r}10 \\
10 \\
9\end{array}$ & $\begin{array}{r}119 \\
106 \\
77\end{array}$ & $\begin{array}{l}0.135 \\
0.135 \\
0.122\end{array}$ & $\begin{array}{l}0.005 \\
0.005 \\
0.009\end{array}$ & $\begin{array}{r}-1.1 \\
1.3 \\
9.0\end{array}$ & $\begin{array}{l}30 \\
28 \\
46\end{array}$ \\
\hline
\end{tabular}

may be explained by the fact that the release methods they used yielded a larger volume change in a longer time. Since no correction for piston displacement time is made, these volume changes will also yield relatively smaller pressure decreases. As a result of this an intrinsically curvilinear relationship may become more or less exponential.
An important new finding consists of the fact that the present results show that the volume change required for attaining zero $\left(\Delta \mathrm{V}_{0}\right)$ is indepent of prerelease pressure. This phenomenon was demonstrated consistently whenever end diastolic pressure was unchanged. A corolary is seen in Figure 9; the slopes of the stress-extension relations are markedly different for 

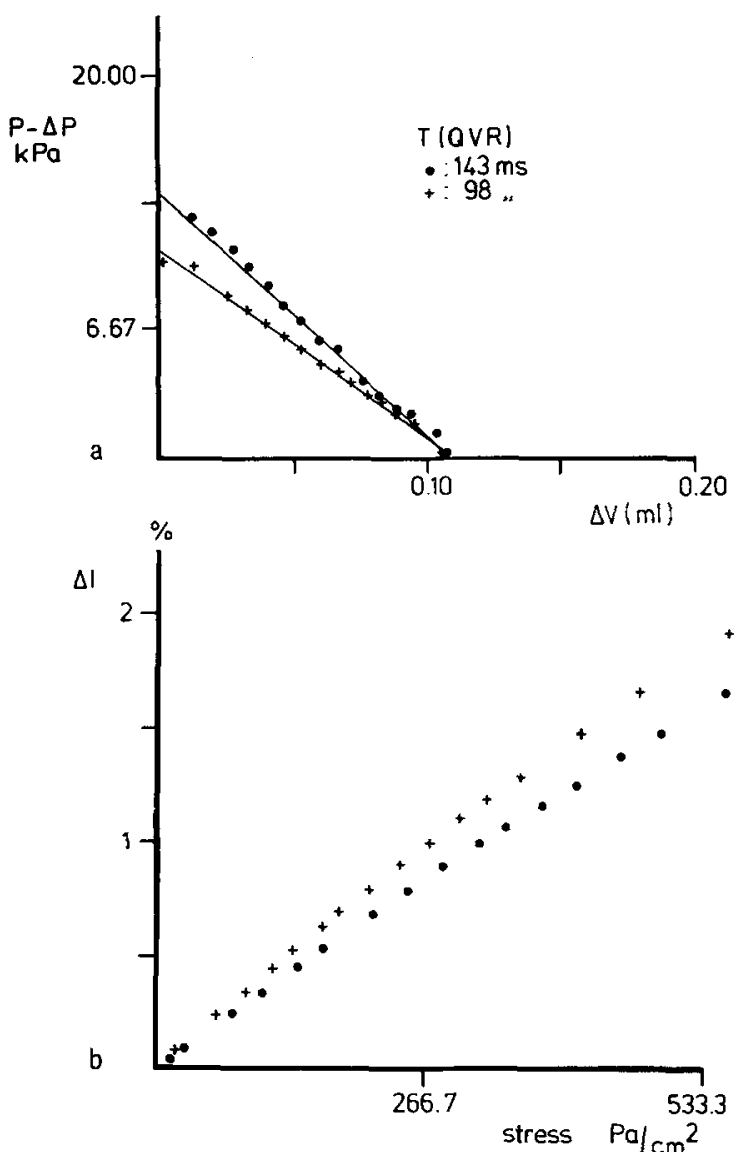

Fig. 9. a (top): Pressure-volume relations at 2 different times during systole (as used in Fig. 9b). b (bottom): The above relations after transformation to midwall stresses and percent of extension of length of the midwall sarcomere in a spherical heart model (Covell et al., 1975)

different moments during contraction. The same result was obtained for different $\mathrm{Ca}^{2+}$ concentrations of the perfusate. This is evidence for the assumption that the stress-extension relations of the actively contracting ventricle depend on time and on the inotropic condition. In the study of Covell et al. this dependency has not been found. It must be noted, however, that the accuracy attained in that study does not allow a final conclusion about the influence of these conditions.

Stiffness values as found during the present study can be appreciated from Figure 9. A 1.6\% decrease of midwall radius was sufficient to attain zero wall tension. This implies a higher stiffness as compared with $4.63 \%$ found by Covell et al. A still appreciably lower stiffness can be estimated from Templeton et al. (1972), who determined ventricular stiffness by inducing sinusoidal volume perturbations.

The present $1.6^{\circ} \%$ can be ascribed to the more elaborate corrections made for the time needed for piston displacement which were not performed by
Covell et al. The sinusoidal method of Templeton on the other hand used a rather low frequency $(12-20 \mathrm{~Hz})$. In this way the heart muscle reacts sufficiently rapidly to diminish the pressure responses appreciably.

With regard to the high stiffness value it can be noted that active stiffness figures concerning papillary muscle as measured with quick release methods have markedly and continuously been increasing during the last decade (Sonnenblick, 1964; Parmley and Sonnenblick, 1967; Pollack and Krueger, 1976). They now approach the value ascribed to skeletal muscle (Ford et al., 1976). Most apparent compliance of papillary muscle seemed to be confined to the damaged ends of the preparation (Krueger and Pollack, 1975; Pollack and Krueger, 1976). It now appears that the active stiffness of the intact ventricle approaches that of the myocardial sarcomere. This gives rise to the question as to from which structure active ventricular quick release compliance arises. Inview of the fact that this compliance as found in this study is time dependent, the presence of a time independent series elastic element seems unlikely.

Acknowledgement. The authors gratefully acknowledge the helpful criticism of this manuscript by Prof. Dr. Ir. J. J. Denier van der Gon.

\section{References}

Abbott, B. C., Mommaerts, W. F. H. M.: A study of inotropic mechanisms in the papillary muscle preparation. J. Gen. Physiol. 42, 533-551 (1959)

Boom, H. B. K.: Elasticity of the heart. Thesis, Utrecht (1971)

Covell, J. W., Taylor, R. R., Sonnenblick, E. H., Ross, J., Jr.: Series elasticity of the Hill model for muscle to the intact left ventricle. Pftuigers Arch. 357, 225-236 (1975)

Epstein, F., McLaughlin, R. J., Bahler, A. S., Sonnenblick, E. H.: Activation independence of myocardial series elasticity. Circulation, Suppl. IV, IV-67 (1973)

Ford, L. E., Huxley, A. F., Simmons, R. M.: The instanteneous elasticity of frog skeletal muscle fibers. J. Physiol. (Lond.) 260, 28P-29P (1976)

Glantz, S. A.: A three element model describes excised cat papillary muscle elasticity. Am. J. Physiol. 228, 284-294 (1975)

Grood, E. S., Mates, R. E., Falsetti, H.: A model of cardiac muscle dynamics. Circ. Res. 35, 184 - 196 (1974)

Jager, G. N.: Electrical model of the human systemic arterial tree. Thesis, Utrecht (1965)

Korteweg, D. J.: Über die Fortpflanzungsgeschwindigkeit des Schalles in elastischen Röhren. Ann. Phys. Chem. Neue Folge 5, $525(1878)$

Krueger, J. W., Pollack, G. H.: Myocardial sarcomere dynamics during isometric contraction. J. Physiol. (Lond.) 251, 627-643 (1975)

McLaughlin, R. J., Sonnenblick, E. H.: Time behaviour of series elasticity in cardiac muscle; real-time measurements by controlled-length techniques. Circ. Res. 34, 798 -811 (1974)

Meiss, R. A., Sonnenblick, E. H.: Dynamic elasticity of cardiac muscle as measured by controlled length changes. Am. J. Physiol. 226, $1370-1381(1974)$ 
Parmley, W. W., Sonnenblick, E. H.: Series elasticity in heart muscle; Its relation to contractile element velocity and proposed muscle models. Circ. Res. 20, 112-123 (1967)

Pollack, G. H., Krueger, J. W.: Sarcomere dynamics in intact cardiac muscle. Eur. J. Cardiol. 4, Suppl., 53-65 (1976)

Schiereck, P., Boom, H. B. K. : Systolic pressure-volume relation of the left ventricle. Arch. Int. Physiol. Biochim. 84, 557-559 (1976)

Pollack, G. H., Huntsman, L. L., Verdugo, P.: Cardiac muscle models; an overextension of series elasticity? Circ. Res. 31, 569-579 (1972)
Sonnenblick, E. H.: Series elastic and contractile elements in heart muscle. Changes in muscle length. Am. J. Physiol. 207, 1330 $-1338(1964)$

Templeton, (i. H., Ecker, P. R., Mitchell, J. H.: Left ventricular stiffness during diastole and systole: the influence of changes in volume and inotropic state. Cardiovasc. Res. 6, 95-100 (1972)

Received December 21, 1977 